Alma Mater Studiorum - Università di Bologna DEPARTMENT OF ECONOMICS

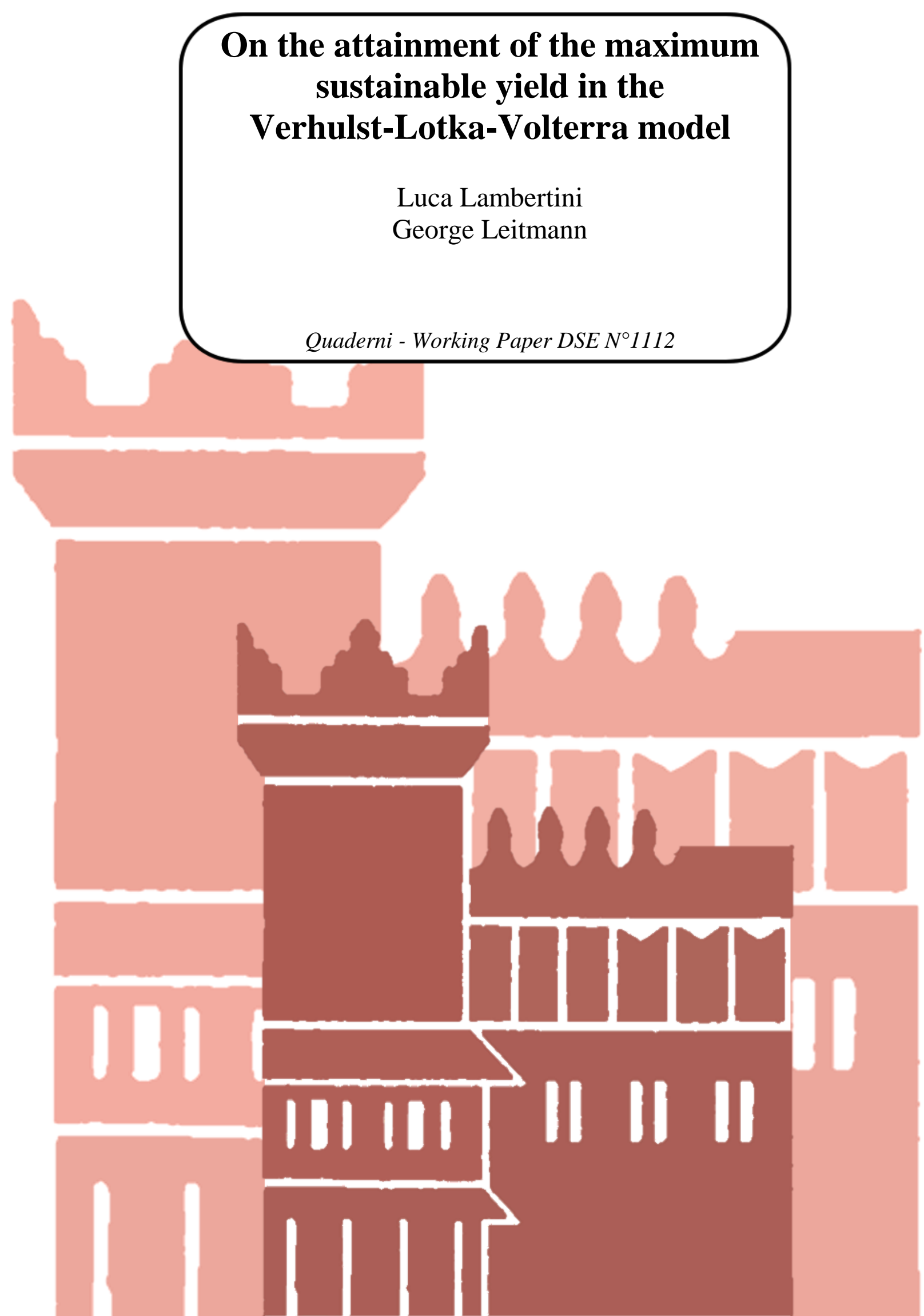




\title{
On the attainment of the maximum sustainable yield in the Verhulst-Lotka-Volterra model
}

\author{
Luca Lambertini ${ }^{\S}$ and George Leitmann $\#$ \\ $\S$ Department of Economics, University of Bologna \\ Strada Maggiore 45, 40125 Bologna, Italy; luca.lambertini@unibo.it \\ \# College of Engineering, University of California at Berkeley \\ 320 McLaughlin Hall, Mailstop 1740, Berkeley, CA 94720-1700; gleit@berkeley.edu
}

October 26, 2017

\begin{abstract}
We reformulate the Verhulst-Lotka-Volterra model of natural resource extraction under the alternative assumptions of Cournot behaviour and perfect competition, to revisit the tragedy of commons vs the possibility of sustainable harvesting. We stress the different impact of demand elasticity on the regulator's possibility of driving industry harvest to the maximum sustainable yield in the two settings. The presence of a flat demand function offers the authority a fully effective regulatory tool in the form of the exogeneous price faced by perfectly competitive firms, to drive their collective harvest rate at the maximum sustainable yield. The same cannot happen under Cournot competition, as in this case the price is endogenous and the regulator's policy is confined to limiting access to the common pool.
\end{abstract}

JEL Codes: C73, L13, Q20, Q28

Keywords: tragedy of commons; sustainability; differential games; resource extraction 


\section{Introduction}

Since Gordon (1954) and Hardin (1968), a leitmotiv of the discussion about the tragedy of commons is our perception of the impact of market power (or the lack thereof) on the preservation of renewable resources or natural species. In a nutshell, considering free access and perfect competition as equivalent, one is induced to think that the impact of perfect competition on a renewable asset's preservation is higher than the impact of any less-thanperfectly competitive industry.

We revisit this issue using the logistic growth model of Verhulst (1838), Lotka (1925) and Volterra (1931) (VLV henceforth), under both Cournot behaviour and perfect competition. Due to the nonlinear dynamics characterising the VLV model, it has been investigated in detail under perfect competition (Pearce and Turner, 1989), while the current literature modelling firms' strategic behaviour in the tragedy of commons has adopted a linear approximation of the original state equation describing the population dynamics, to generate linear and nonlinear feedback solutions. ${ }^{1}$ This simplified version indeed calls for a feedback solution as the linearity of the state dynamics implies that the open-loop solution is unstable (see, for instance, Fujiwara, 2008; and Lambertini and Leitmann, 2013). Its drawback is that abandoning the logistic growth curve for a linear state equation implies assuming a constant reproduction rate for the natural resource, and therefore eliminates a fundamental element of the VLV model, namely, the maximum sustainable yield, which is the peak of the concave growth rate, and the ideal target of any public authority interested in a resource exploitation pattern sustainable in the long run without compromising the survival of the stock. In fact, the analysis in Pearce and Turner (1989) focusses on the conditions under which monopoly (or a cartel) or perfect competition may harvest at the maximum sustainable yield at any point in time. ${ }^{2}$

\footnotetext{
${ }^{1}$ Among the many contributions in this vein, see Benchekroun (2003, 2008); Fujiwara (2008); Colombo and Labrecciosa (2013a,b, 2015); Lambertini and Mantovani (2014, 2016); and Lambertini (2016).

${ }^{2} \mathrm{~A}$ related but not equivalent stream of literature discusses the possibile arising of
} 
Our approach is based on the strong time consistency of the open-loop solution of the VLV model, irrespective of the nature or intensity of competition characterising the market. Under both Cournot and perfect competition, the model produces two steady state equilibria which, in general, are located symmetrically to the left and right of the maximum sustainable yield. In both cases, that lying to the right is stable, while the other is not.

The main results of our analysis can be outlined as follows. If market demand is downward sloping and firms behave à la Cournot, there exists a subset of parameters in which the regulator may limit access to the common pool so as to drive industry harvest as close as possible to the maximum sustainable level, without reaching it. If instead perfect competition prevails and demand is flat, the total lack of firms' control on price offers an additional tool to the policy maker who can regulate price to achieve the fully sustainable harvest (i.e., the maximum sustainable yield) for any number of firms in the industry. Hence, there emerges that what really matters is not free vs regulated access to the commons, but rather the elasticity of demand: an infinitely elastic market demand offers the possibility of regulating the exogenously given price to attain the goal of sustainability.

The structure of the paper is the following. Section 2 describes the model and Cournot behaviour. The perfectly competitive setting is in section 3 . Concluding remarks are in section 4 .

\section{Setup and Cournot competition}

Consider a market existing over continuous time $t \in[0, \infty)$, being supplied by $n \geq 1$ identical firms exploiting a renewable resource $X(t)$ to produce a homogeneous final good sold to consumers. The state dynamics is as in the VLV model,

$$
\dot{X}(t)=\delta X(t)[1-\beta X(t)]-Q(t)
$$

efficient equilibria, possibly by means of cooperation among agents. Once again, efficiency does not in general imply the attainment of a harvest at the maximum sustainable yield. See, e.g., Dockner and Kaitala (1993), Ehtamo and Hämäläinen (1993), and Martin-Herran and Rincon-Zapatero (2005), among others. 
in which $\beta$ and $\delta$ are positive constants, and $Q(t)=\sum_{i=1}^{n} q_{i}(t)$ is the sum of the $n$ firms' individual harvest at any instant. With an appropriate choice of measure, $q_{i}(t)$ and $Q(t)$ are also the instantaneous individual and industry output levels. Note that, if $\beta=0$, then (1) collapses to the linear state dynamics used in the aforementioned literature, and is responsible of the instability of the open-loop solution for any $n$.

Let the instantaneous demand and individual cost function be $p(t)=$ $a-Q(t)$ and $C_{i}(t)=c q_{i}^{2}(t)$, respectively. As a result, firm $i$ 's profit function is $\pi_{i}(t)=\left[p(t)-c q_{i}(t)\right] q_{i}(t)$. Firm $i$ has choose harvest $q_{i}(t)$ so as to maximise the discounted profit flow

$$
\Pi_{i}(t)=\int_{0}^{\infty} \pi_{i}(t) e^{-\rho t} d t
$$

under the constraint posed by (1). The Hamiltonian function of firm $i$ is therefore

$$
\mathcal{H}_{i}(t)=\left[p(t)-c q_{i}(t)\right] q_{i}(t)+\lambda_{i}(t)[\delta X(t)(1-\beta X(t))-Q(t)]
$$

to be maximised w.r.t. $q_{i}(t)$, the initial condition being $X_{0}=X(0)>0$.

Suppose firms operate under open-loop information. The first order condition (FOC) taken w.r.t. $q_{i}$ is (henceforth, we omit the explicit indication of the time argument):

$$
\frac{\partial \mathcal{H}_{i}}{\partial q_{i}}=a-2(1+c) q_{i}+\sum_{j \neq i} q_{j}-\lambda_{i}=0
$$

and the costate equation is

$$
\dot{\lambda}_{i}=[\delta(2 \beta X-1)+\rho] \lambda_{i}
$$

This implies that the costate dynamics is described by a differential equation is separable variables, admitting the solution $\lambda_{i}=0$ at any time, for all $i=1,2, \ldots n$. This fact, of course, means that profit-seeking firms do no care about the preservation of the renewable resource stock. However, it also implies that the open-loop solution of the game is indeed subgame perfect 
(or, strongly time consistent), although the structure of the game is not linear in the state variable. Indeed, the game is state-redundant (see Dockner et al., 2000). ${ }^{3}$

Imposing full symmetry across the population of firms and substituting $\lambda=0$ in (4), the FOC delivers the static Cournot-Nash solution $q^{C N}=$ $a /(n+1+2 c)$, which is invariant in the resource stock. Then, noting that

$$
\dot{X} \gtreqless 0 \text { for all } \delta X(1-\beta X) \gtreqless Q^{C N}=n q^{C N}
$$

one can draw the relevant phase diagram in the state-control space, as illustrated in Figure 1. The horizontal arrows appearing along the flat line at $Q^{C N}$ describe the dynamics of the stock implied by (6).

Figure 1 The phase diagram under Cournot competition

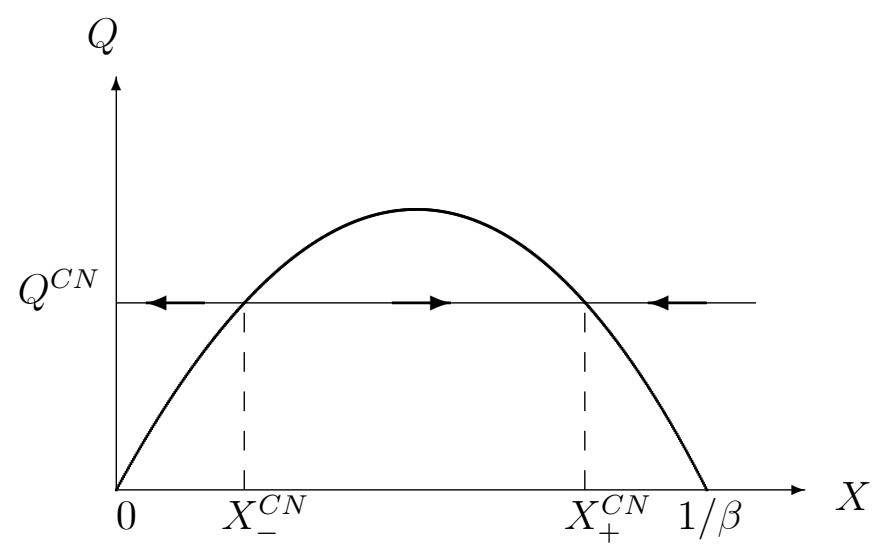

The steady state levels of the stock are

$$
X_{ \pm}^{C N}=\frac{\delta(n+1+2 c) \pm \sqrt{\delta(n+1+2 c)[\delta(n+1+2 c)-4 \beta a n]}}{2 \beta \delta(n+1+2 c)}
$$

which belong to $\mathbb{R}^{+}$for all $\beta \in(0, \delta(n+1+2 c) /(4 a n)]$. The steady state point $\left(X_{-}^{C N}, Q^{C N}\right)$ is unstable while the second, $\left(X_{+}^{C N}, Q^{C N}\right)$, is stable, as one can see from Figure 1. Moreover, $\partial X_{-}^{C N} / \partial n>0$ and $\partial X_{+}^{C N} / \partial n<0$.

\footnotetext{
${ }^{3}$ This property of the VLV model was originally pointed out by Goh et al. (1974). See also Leitmann (1973).
} 
More importantly, if $\delta(n+1+2 c)-4 \beta a n=0$, the horizontal locus $Q^{C N}$ is tangent to the concave locus describing the undisturbed growth rate of the natural resource. Should this happen (and it may do so in correspondence of infinitely many values of the parameter set $\{\beta, \delta, a, c, n\})$, then industry harvest would correspond to the maximum sustainable yield $M S Y=1 /(2 \beta)$. This would be an unstable case, as Figure 2 shows.

Figure 1 The phase diagram under Cournot competition

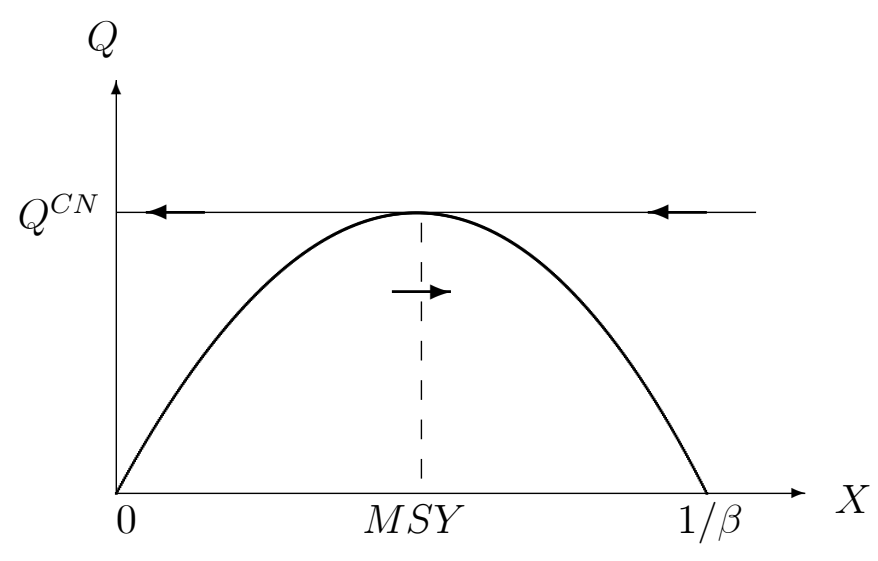

However, note that $M S Y=1 /(2 \beta)$ at $n_{M S Y}=\delta(1+2 c) /(4 \beta a-\delta)>0$ for all $a>\delta /(4 \beta)$, and

$$
n_{M S Y} \geq 1 \Leftrightarrow a \leq \frac{(1+c) \delta}{2 \beta}
$$

with

$$
\frac{(1+c) \delta}{2 \beta}>\frac{\delta}{4 \beta}
$$

Accordingly, we may formulate the following

Proposition 1 For all

$$
a \in\left(\frac{\delta}{4 \beta}, \frac{(1+c) \delta}{2 \beta}\right],
$$


in correspondence of the lowest integer $\widetilde{n}>n_{M S Y}$, the industry harvest is as close as possible to the MSY and the resulting steady state is stable, with an equilibrium stock equal to $X_{+}(\widetilde{n})$.

Hence, the regulator may drive the industry harvest close to the $M S Y$ by limiting access to the commons at $\widetilde{n}$, which, if $n_{M S Y}$ is an integer, will be equal to $n_{M S Y}+1$. The above proposition says that there exists an intermediate range of values of the choke price $a$ such that the maximum sustainable yield is attained by an admissible industry structure (i.e., at least in monopoly). It is worth noting that the same condition can be reformulated by saying that $n_{M S Y} \geq 1$ for all

$$
\delta \in\left[\frac{2 \beta a}{1+c}, 4 \beta a\right)
$$

or, in a range of values of the parameter which would measure the natural growth rate of the resource in the linear approximation of the VLV model.

Before proceeding to the analysis of the impact of perfect competition, it is worth observing that the Cournot oligopoly reproduces a perfectly competitive industry in the limit, as $n$ tends to infinity under free entry, but does so with a downward sloping demand function - which is not infinitely elastic

- and an endogenous market price. These are typically not the assumptions adopted to describe a perfectly competitive industry in which firms exert no control whatsoever on price.

\section{Perfect competition}

Now we turn to the case in which the $n$ firms are perfectly competitive and behave as price-takers, which is the scenario examined in Pearce and Turner (1989). The demand function is infinitely elastic and the price $p$ is exogenous and time-invariant. Consequently, the instantaneous profit function of firm $i$ is $\pi_{i}(t)=\left[p-c q_{i}(t)\right] q_{i}(t)$. The Hamiltonian function is defined as in (3), but the presence of a constant market price modifies the FOC taken w.r.t. 
individual harvest as follows:

$$
\frac{\partial \mathcal{H}_{i}}{\partial q_{i}}=p-2 c q_{i}-\lambda_{i}=0
$$

The costate equation obviously coincides with (5), which again implies $\lambda_{i}=0$ at all times. As a result, the perfectly competitive individual harvest solving (11) is $q^{P C}=p /(2 c)$. This generates competitive equilibrium profits $\pi^{p c}=$ $p^{2} /(4 c)$ at all times, independently of the number of firms, provided the resource stock remains positive forever.

In steady state, the resource stock associated with $q^{P C}=p /(2 c)$ is

$$
X_{ \pm}^{p c}=\frac{\sqrt{\delta c} \pm \sqrt{\delta c-2 \beta n p}}{2 \beta \sqrt{\delta c}} \in \mathbb{R}^{+} \forall \delta>\frac{2 \beta n p}{c}
$$

The phase diagram is analogous to that portrayed in Figure 1. Moreover, as under Cournot behaviour, the steady state characterised by $X_{+}^{p c}$ is stable, while the other is not, for the same reasons. And, once again, $\partial X_{-}^{p c} / \partial n>0$ and $\partial X_{+}^{p c} / \partial n<0$.

Looking at (12), it is evident that $X_{ \pm}^{p c}=X_{M S Y}$ iff $\delta c-2 \beta n p=0$. This gives the regulator an additional degree of freedom, as the price can be manoeuvred to drive $X_{+}^{p c}$ arbitrarily close to the $M S Y$, still preserving the stability of the resulting steady state, for any number of firms. Indeed, from the policy maker's standpoint, the problem boils down to regulating $n p$ (that is, either access to the common pool or price, or both) to minimise the difference between $X_{+}^{p c}$ and $X_{M S Y}$. While in the Cournot setting the integer problem must be explicitly accounted for, here the additional tool offered by the exogenous price opens the possibility of reaching any $X_{+}^{p c}=X_{M S Y}+\varepsilon$, with $\varepsilon$ positive and arbitrarily small.

The foregoing discussion can be summarised in the following:

Proposition 2 Under perfect competition, there exist infinitely many pairs $(n, p)$ satisfying $n p=\delta c /(2 b)$, such that the industry harvest equals the MSY.

The joint assessment of Propositions 1-2 deserves some additional remarks. First, one has to consider that, under Cournot competition, the 
integer problem must explicitly be accounted for, while the presence of an arbitrarily large number of firms in a perfectly competitive industry poses no issue in view of the fact that the public authority can take $n$ as given and just regulate market price. Second, Proposition 1 identifies a parametric restriction adding itself up to the integer problem, and it basically says that, by regulating access to the common pool, the regulator may drive industry harvest close to the MSY without ever reaching it. This, of course, holds as well in the special case in which the Cournot industry collapses to a pure monopoly at $n=1$. Put differently, the integer problem causes the Cournot-Nash industry harvest (even under regulated access) to exceed the MSY strictly. This is not the case under perfect competition, as the integer problem is no obstacle to the regulator's action when the demand is perfectly elastic.

This reveals a flaw in our perception of the impact of competition (or, conversely, of market power) on the resource stock in the long run, which has long been debated, at least since the early analysis dating back to Pearce and Turner (1989). The point is that free access and perfect competition have been usually taken as synonymous in the literature on the economics of common pools' exploitation, while they are not. Free access to the commons implies that there is no upper limit to the number of firms extracting the resource, other than their profit incentives. If we conceive perfect competition as a scenario in which firms have no control on price and demand is flat, then it clearly appears that free access and perfect competition are not the same thing. Indeed, free access may also characterise an oligopoly game whose limit properties under free entry include marginal cost pricing, but this does not apply to the equilibrium configuration of such an industry for any finite number of firms. The foregoing analysis shows that the ultimate consequence of the tragedy of commons, namely, resource exhaustion (or, the extinction of the species) can be more easily avoided under perfect competition than in any other less competitive situation in which some population of agents do have a degree of market power and therefore endogenously determine market price along a negatively sloped demand function. 


\section{Concluding remarks}

Our revisitation of the VLV model has shown that properly distinguishing between free access to the commons and perfect competition offers the possibility of identifying a policy based on price regulation inducing a perfectly competitive industry to harvesting arbitrarily close to the MSY. The analogous approach to the same problem under Cournot competition has highlighted that the integer problem matters in a strategic oligopoly, preventing the regulator to replicate the same outcome. This is due to the endogeneity of price when firms have market power, obliging the public authority to explicitly regulate access to the commons. 


\section{References}

[1] Benchekroun, H. (2003), "Unilateral Production Restrictions in a Dynamic Duopoly", Journal of Economic Theory, 111, 214-39.

[2] Benchekroun, H. (2008), "Comparative Dynamics in a Productive Asset Oligopoly", Journal of Economic Theory, 138, 237-61.

[3] Colombo, L. and P. Labrecciosa (2013a), "Oligopoly Exploitation of a Private Property Productive Asset", Journal of Economic Dynamics and Control, 37, 838-53.

[4] Colombo, L. and P. Labrecciosa (2013b), "On the Convergence to the Cournot Equilibrium in a Productive Asset Oligopoly", Journal of Mathematical Economics, 49, 441-45.

[5] Colombo, L., and P. Labrecciosa (2015), "On the Markovian Efficiency of Bertrand and Cournot Equilibria", Journal of Economic Theory, 155, $332-58$.

[6] Dockner, E.J. and V. Kaitala (1989), "On Efficient Equilibrium Solutions in Dynamic Games of Resource Management", Resource and Energy Economics, 11, 23-34.

[7] Dockner, E.J., Jørgensen, S., Long, N.V. and Sorger, G. (2000). Differential Games in Economics and Management Science, Cambridge, Cambridge University Press.

[8] Ehtamo, H. and R.P. Hämäläinen (1993), "A Cooperative Incentive Equilibrium for a Resource Management Problem", Journal of Economic Dynamics and Control, 17, 659-78.

[9] Fujiwara, K. (2008), "Duopoly Can Be More Anti-Competitive than Monopoly", Economics Letters, 101, 217-19.

[10] Goh, B., G. Leitmann and T. Vincent (1974), "Optimal Control of the Prey-Preditor System", Journal of Mathematical Biosciences, 19, 26386. 
[11] Gordon, H.S. (1954), "The Economic Theory of a Common-Property Resource: The Fishery", Journal of Political Economy, 62, 124-42.

[12] Hardin, G. (1968), "The Tragedy of the Commons", Science, 162, 124348.

[13] Lambertini, L. (2016), "Managerial Delegation in a Dynamic Renewable Resource Oligopoly", in H. Dawid, K. Doerner, G. Feichtinger, P. Kort and A. Seidl (eds), Dynamic Perspectives on Managerial Decision Making: Essays in Honor of Richard F. Hartl, Heidelberg, Springer.

[14] Lambertini, L. and G. Leitmann (2013), "Market Power, Resource Extraction and Pollution: Some Paradoxes and a Unified View", in J. Crespo Cuaresma, T. Palokangas and A. Tarasjev (eds), Green Growth and Sustainable Development, Heidelberg, Springer, 143-64.

[15] Lambertini, L. and Mantovani, A. (2014), "Feedback Equilibria in a Dynamic Renewable Resource Oligopoly: Pre-emption, Voracity and Exhaustion", Journal of Economic Dynamics and Control, 47, 115-22.

[16] Lambertini, L. and A. Mantovani (2016), "On the (In)stability of Nonlinear Feedback Solutions in a Dynamic Duopoly with Renewable Resource Exploitation", Economics Letters, 143, 9-12.

[17] Leitmann, G. (1973), "A Minimum Principle for a Population Equation", Journal of Optimization Theory and Applications, 9, 155-56.

[18] Martin-Herran, G. and J.P. and Rincon-Zapatero (2005), "Efficient Markov Perfect Nash Equilibria: Theory and Application to Dynamic Fishery Games", Journal of Economic Dynamics and Control, 29, 107396.

[19] Lotka, A.J. (1925), Elements of Physical Biology, Philadelphia, Williams and Wilkins.

[20] Pearce, D.W. and R.K. Turner (1989), Economics of Natural Resources and the Environment, Hemel Hempstead, Harvester-Wheatsheaf. 
[21] Verhulst, P.H. (1838), "Notice sur la loi que la population poursuit dans son accroissement", Correspondance mathématique et physique, 10, 113-21.

[22] Volterra, V. (1931), "Variations and Fluctuations of the Number of Individuals in Animal Species Living Together", in R.N. Chapman (ed.), Animal Ecology, New York, McGraw-Hill. 


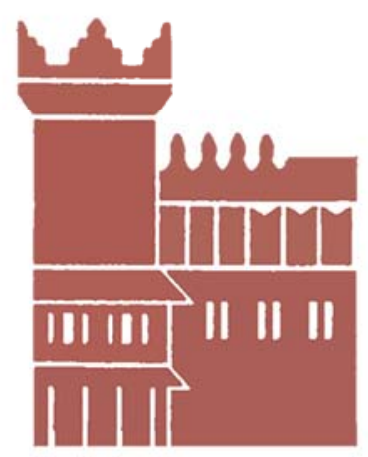

Alma Mater Studiorum - Università di Bologna DEPARTMENT OF ECONOMICS

Strada Maggiore 45

40125 Bologna - Italy

Tel. +39051 2092604

Fax +390512092664

http://www.dse.unibo.it 